Int. J. Odontostomat.,

4(1):71-80, 2010.

\title{
Aplicaciones Periodontales a Ortodoncia
}

\author{
Periodontal Applications to Orthodontic
}

Fernando Holmberg Peters ${ }^{* * *}$; Felipe Holmberg Peters ${ }^{* * *}$; Hans Holmberg Peters ${ }^{* * * *}$ \& Paulo Sandoval ${ }^{* \star * * *}$

HOLMBERG, P. F.; HOLMBERG P. F.; HOLMBERG P. H. \& SANDOVAL, P. Aplicaciones periodontales a ortodoncia. Int. J. Odontostomat., 4(1):71-80, 2010.

RESUMEN: El presente artículo tiene por objetivo dar a conocer cuatro procedimientos peridodontales de tipo quirúrgico que pueden ser de gran utilidad para el ortodoncista y que deben ser considerados durante la planificación ortodóncica.

PALABRAS CLAVE: regeneración tisular guiada (RTG), relleno óseo, corticotomía.

\section{INTRODUCCIÓN}

Regeneración tisular guiada. Uno de los procedimientos reconstructivos más documentados en periodoncia es la regeneración tisular guiada (RTG) (Thailander, 1996; Brown, 1973; Ericsson et al., 1977). En esta técnica se implanta quirúrgicamente una barrera biocompatible en forma de membrana (reabsorbible o no reabsorbible), para aislar y proteger el defecto óseo. En la lesión protegida por la membrana, puede producirse regeneración de tejido conectivo y de hueso. El fundamento biológico de este procedimiento es que con él se evita la migración del tejido epitelial al interior del defecto óseo, dando tiempo para la cicatrización del hueso y otros tejidos de inserción, situación que no ocurre durante la cicatrización normal debido a que los tejidos epiteliales migran rápidamente hacia el interior de la herida y no permiten la regeneración (Vanarsdall, 1995).

\section{CASO CLINICO 1}

A continuación se presenta el caso de un paciente de sexo masculino, 23 años de edad, desarmonía dentomaxilar con discrepancia de espacio negativa y erupción ectópica de diente 1.3 (Figs. 1 y 2).

Al examen periodontal pérdida de cortical vestibular, falta de encía adherida y lesión cariosa dentinaria profunda en relación a diente 1.3 por lo cual se indica la exodoncia de este diente y se planifica la utilización de RTG como complemento a la terapia ortodóncica en relación al diente 1.5 con el objetivo de aumentar el volumen de los tejidos periodontales e idealmente regenerar la tabla ósea vestibular para evitar fenestraciones o dehiscencias óseas y posibles recesiones gingivales.

Se levanta un colgajo de espesor completo y se puede observar la ausencia de tabla vestibular en relación al diente 1.3 (Figs. 3 y 4). Se realiza la exodoncia del diente 1.3 (Fig. 5) y como complemento a la RTG se decide utilizar un injerto óseo particulado para lo cual se realiza la exodoncia del diente 1.8 y se procede a la extracción de hueso alveolar (Figs. 6 y 7 ).

Este hueso autógeno ideal por sus propiedades osteogénicas es combinado con hueso humano liofilizado que posee propiedad osteoconductora (Fig. 8) y es aplicado en el sitio quirúrgico previamente activado (Fig. 9).

Posteriormente se utiliza una membrana colágena previamente individualizada (Figs. 10 y 11) y finalmente se sutura el colgajo (Fig. 12).

* Alumno Programa de Especialización en Ortodoncia y Ortopedía DentoMaxiloFacial, Universidad de La Frontera, Chile.

** Especialista en Periodoncia, Universidad de Chile, Chile.

*** Alumno de Odontología; Univesidad de Antofagasta, Chile.

**** Alumno de Odontología; Univesidad San Sebastián, Puerto Montt, Chile.

*****Jefe Programa de Especialización en Ortodoncia y Ortopedía DentoMaxiloFacial, Universidad de La Frontera, Chile. 
HOLMBERG, P. F.; HOLMBERG P. F.; HOLMBERG P. H. \& SANDOVAL, P. Aplicaciones periodontales a ortodoncia. Int. J. Odontostomat., 4(1):71-80, 2010.


Fig. 2B

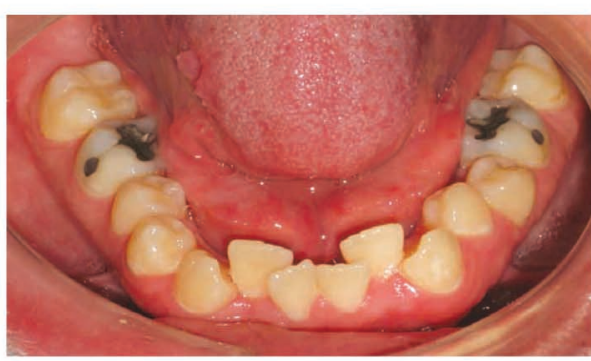

Fig. 2E





Fig. 5

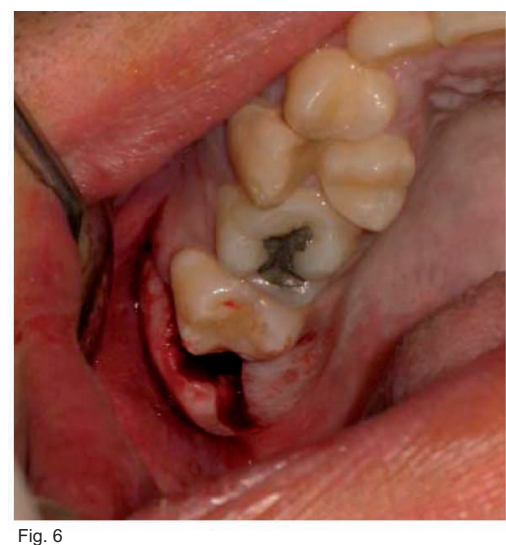

Fig. 6

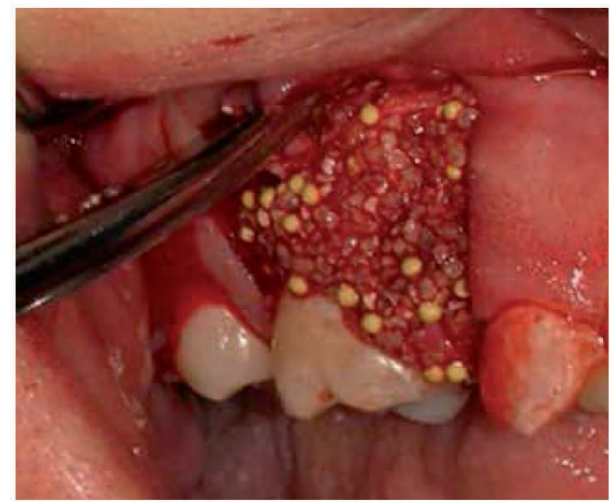

Fig. 9

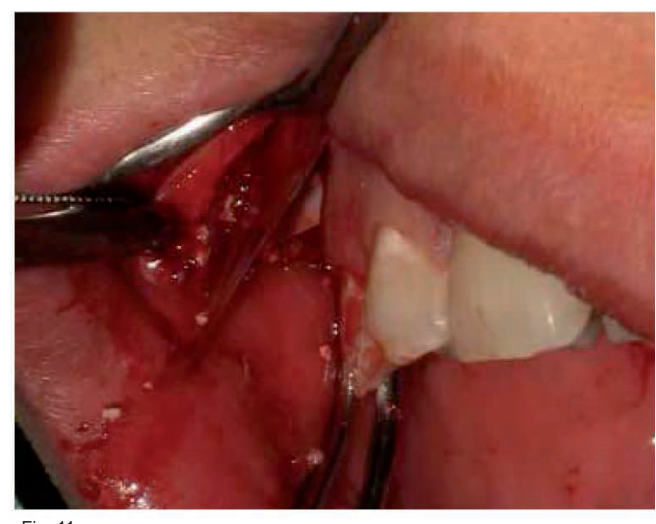

Fig. 11

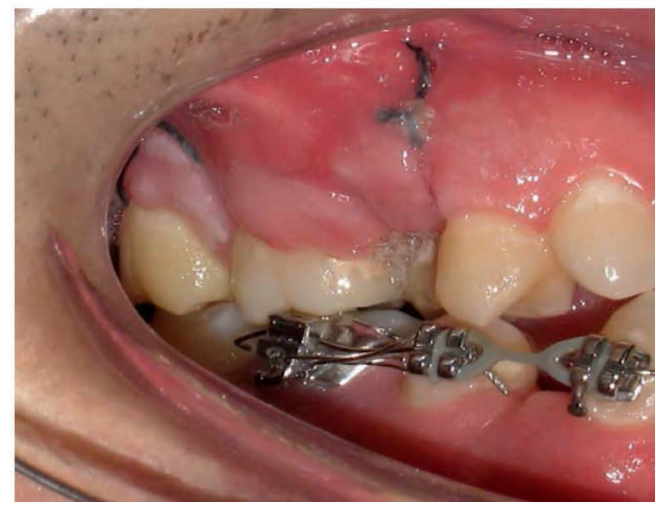


Control postquirúrgico a la semana (Fig. 13), a las tres semanas es evidente clínicamente el aumento de volumen de los tejidos como resultado del procedimiento regenerativo (Fig. 14). Control clínico a los 12 meses de realizado el procedimien- to quirúrgico (Fig. 15)

Control tomográfico a los 8 meses post quirúrgico, la imagen muestra la presencia de una zona radioopaca compatible con tejido óseo (Fig. 16).

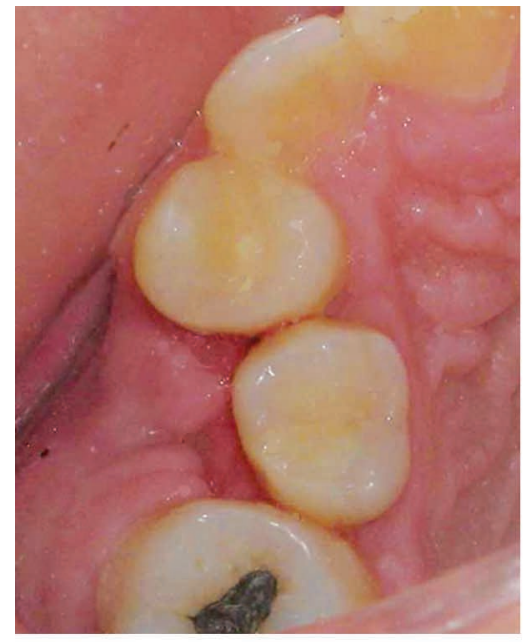

Fig. 14

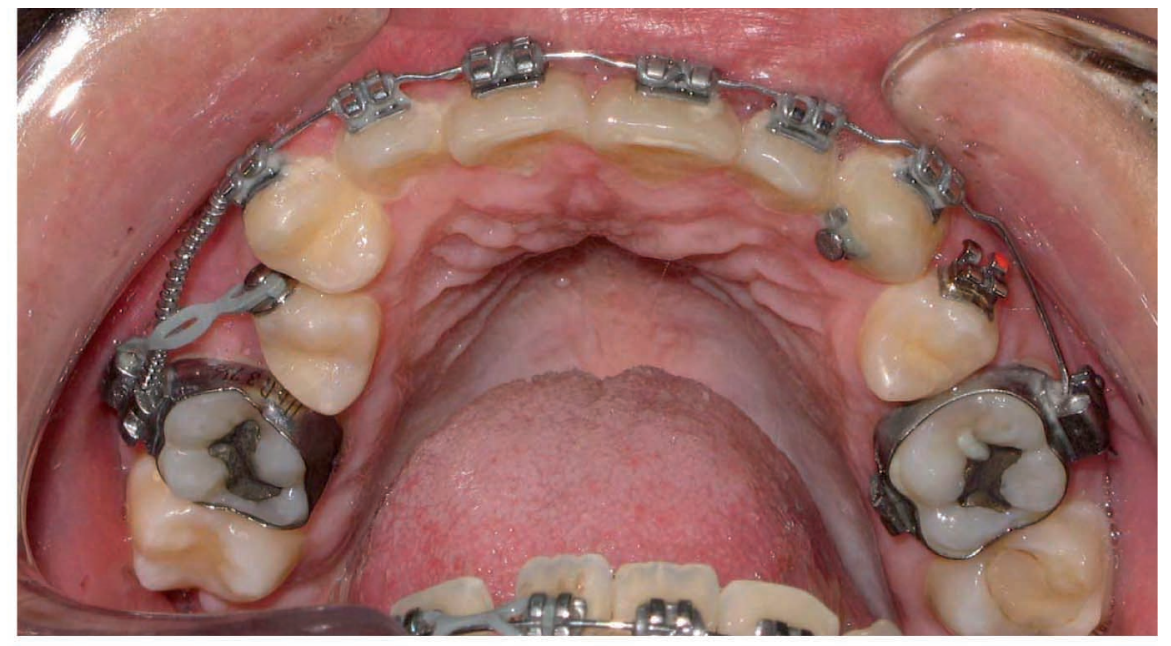

Fig. 15

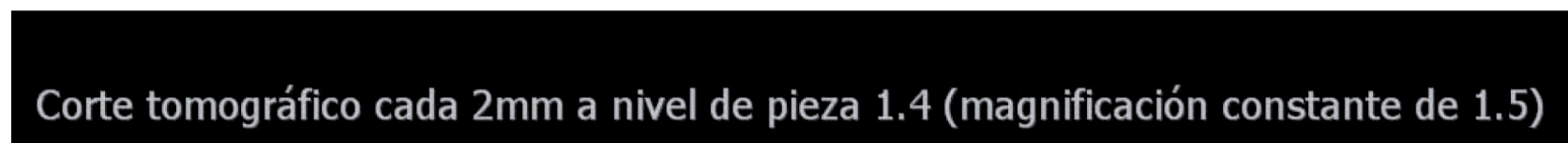
Distal
Mesial
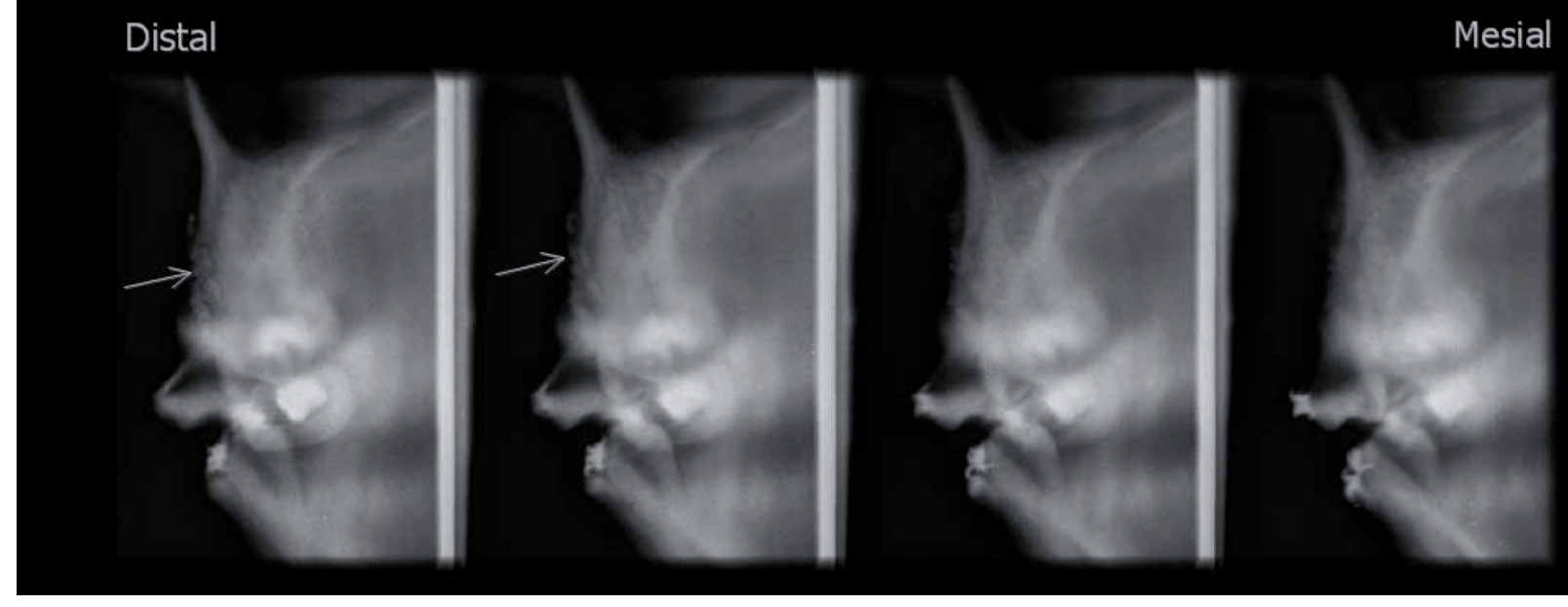

Fig. 16

Relleno óseo y colgajo desplazado a coronal. En relación a movimientos dentarios hacia defectos óseos, se puede iniciar la movilización dentaria hacia áreas con hueso reducido siempre que se ejerzan fuerzas leves y se mantenga una higiene oral excelente. Sin embargo se ha observado invaginaciones gingivales marcadas. Estudios histológicos y con tomografía computarizada en humanos mostraron la formación de dehiscencias óseas por vestibular o lingual (Diedrich, 1996). En cuanto al movimiento ortodóncico a través de rebordes alveolares muy atróficos, existe la posibilidad de usar procedimientos regenerativos (Stelzel \& Flores-de-Jacoby, 1995; 1998). 
En diferentes estudios se ha combinado el tratamiento por colgajos con la colocación de injertos óseos o materiales de implante dentro de los defectos óseos, con el fin de estimular la regeneración periodontal. Los diversos materiales de injerto e implantes usados hasta ahora pueden ser ubicados en cuatro categorías:

- Injertos autógenos: injertos transferidos de una posición a otra dentro del mismo individuo (zona donante intraoral o extraoral).

- Aloinjertos: injertos transferidos entre miembros de la misma especie genéticamente diferentes (MFDBA, DFDBA).

- Heteroinjertos o xenoinjertos: injertos tomados de un donante de otra especie. (Bio-Oss $®$ )

- Materiales aloplásticos: materiales para implantes inertes utilizados como sustitutos de los injertos de hueso (fosfato tricálcico beta, hidroxiapatita).

Las razones para usar injertos óseos o materiales aloplásticos es la suposición que el material puede contener células óseas neoformadoras (osteogénesis), o servir como andamiaje para la neoformación ósea (osteoinducción) o también que la matriz de los injertos óseos contiene sustancias inductoras de hueso (osteoinducción) que podrían estimular tanto la neoformación de hueso alveolar como la formación de una nueva inserción.

La evidencia concluye que la regeneración periodontal en humanos es posible tras el uso de injertos óseos, de la RTG y tras la combinación entre ellos (Campos et al., 2007).

\section{CASO CLINICO 2}

Paciente de sexo femenino, 22 años con desarmonía dentomaxilar y discrepancia de espacio negati- va por lo cual se planifica tratamiento de ortodoncia reductor solicitándose a su dentista la exodoncia de 4 premolares (segundos superiores y primeros inferiores).

Al siguiente control la paciente presenta lesión en comisura labial (Fig. 17) y al examen intraoral signos de exodoncia traumática de diente 4.4 con la consecuente pérdida ósea y de encía adherida (Fig. 18)

Radiograficamente se observa la gran perdida de hueso alveolar en relación al sitio de extracción (Fig. 19). Se planifica la realización de una cirugía de relleno óseo más colgajo desplazado coronalmente para ganar volumen y encía adherida (Figs. 20 y 21). Control clínico y radiográfico a los 3 meses posquirúrgico (Figs. 22 y 23).

Corticotomía. La corticotomía es un procedimiento quirúrgico que fue descrito por primera vez como un acelerador del movimiento ortodóncico en 1893 por L.C Bryan. En la actualidad ha sido popularizado y modificado por Wilcko et al. (2001) siendo patentado como PAOO: periodontally accelerated osteogenic orthodontics.

La técnica quirúrgica consiste en una corticotomía vertical interproximal por vestibular y lingual de las raíces dentarias conectadas por corticotomías supraapicales horizontales para facilitar la luxación de los bloques óseos, complementadas con relleno óseo de la zona para disminuir el riesgo de dehisencias óseas y la consecuente formación de reseciones gingivales (Nowzari et al., 2008).

Dentro de las aplicaciones de esta técnica en adultos se encuentra la aceleración del movimiento dentario, disminución del riesgo de reabsorción radicular; corrección de mordidas abiertas, facilitación de la expansión maxilar, intrusión de molares entre otros (Akay et al., 2009; Oliveira et al., 2008; Fischer, 2007; Lino et al., 2007).

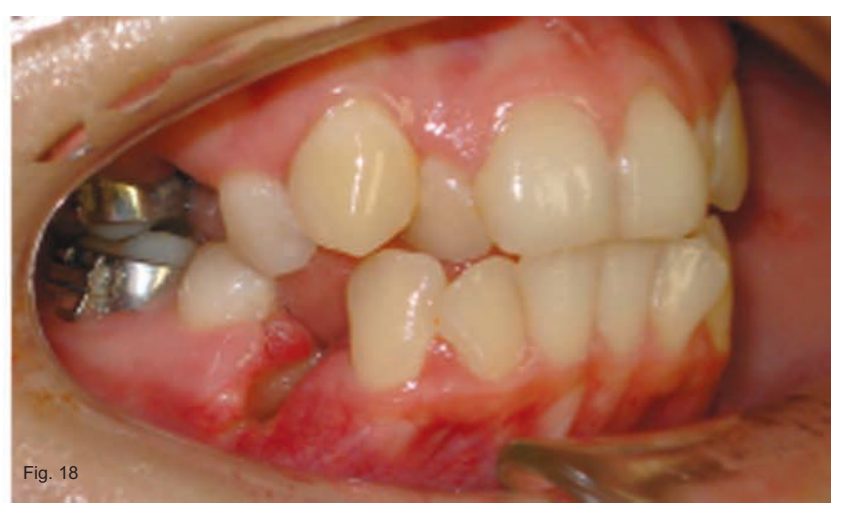




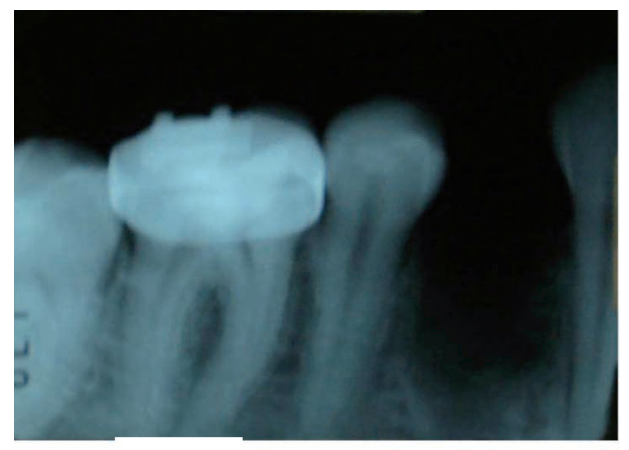

Fig. 19

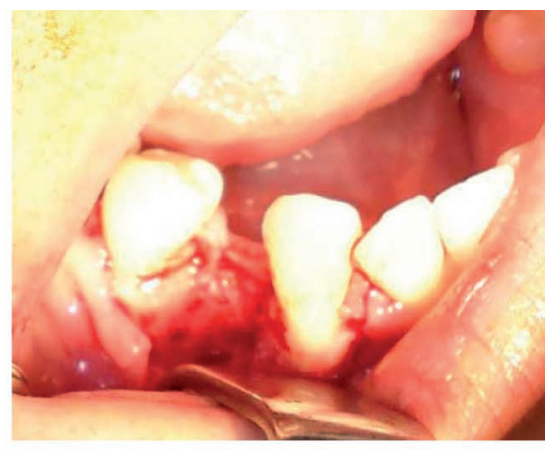

Fig. 20

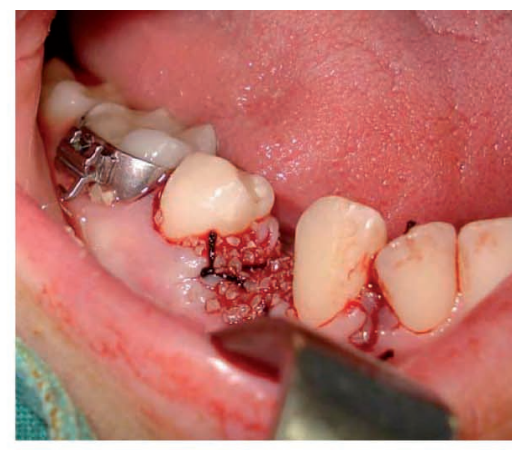

Fig. 21
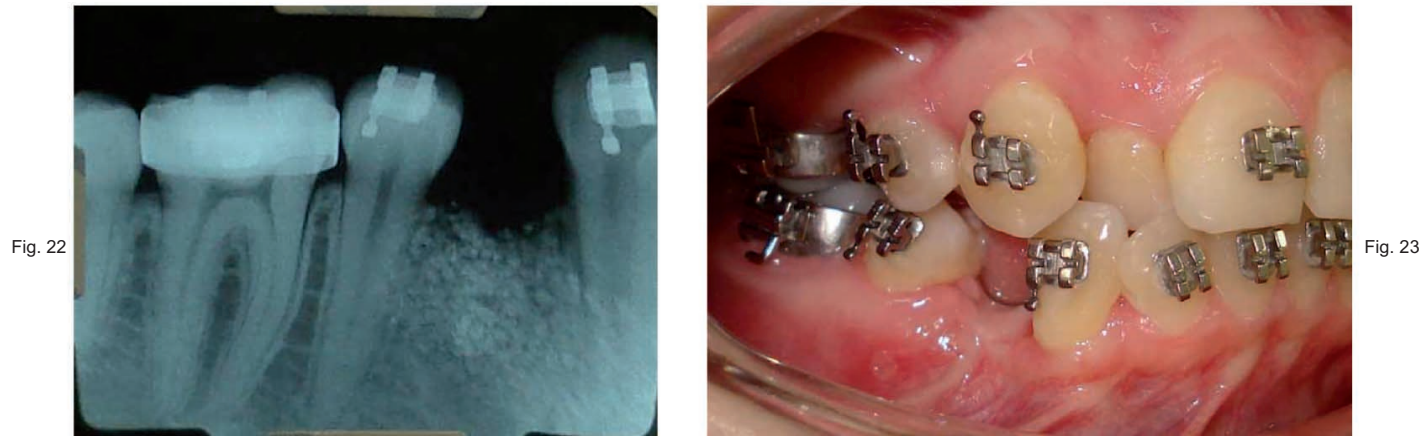

\section{CASO CLÍNICO 3}

Paciente masculino de 21 años, presenta desarmonía dentomaxilar con mordida cruzada bilateral y fractura coronoradicular de diente 1.1. Como parte del tratamiento se planifica una corticotomía maxilar localizada para facilitar la expansión maxilar.

En la Figura 24 se observa la elevación de un colgajo de espesor total en la zona a expandir, posteriormente se procede a realizar la corticotomía (Fig. 25). Según el protocolo de Wilcko se complementa la corticotomía con un relleno óseo (Fig. 26).

Se observa el control postquirúrgico a los 7 días (Fig. 27) y a las 3 semanas (Fig. 28).

Verticalización quirúrgica de molares. Se desconoce la incidencia de impactación de segundos molares, aunque se manejan cifras de sobre 3 por cada 1000 segundos molares inferiores (Varpio \& Wellfelt, 1988; Johnson, 1997).

Entre las opciones de tratamiento se encuentran: Exodoncia de segundo molar impactado y erupción mesial del tercer molar (poco predecible).

Exodoncia de segundo molar impactado y mesialización ortodoncica del tercer molar.
Exodoncia de segundo molar impactado y autotransplante del tercer molar.

Extrusión ortodócica del segundo molar.

Verticalización quirúrgica del segundo molar impactado.

Este último procedimiento es fácil, de baja morbilidad y con buen pronostico en el tiempo (Pogrel, 1995).

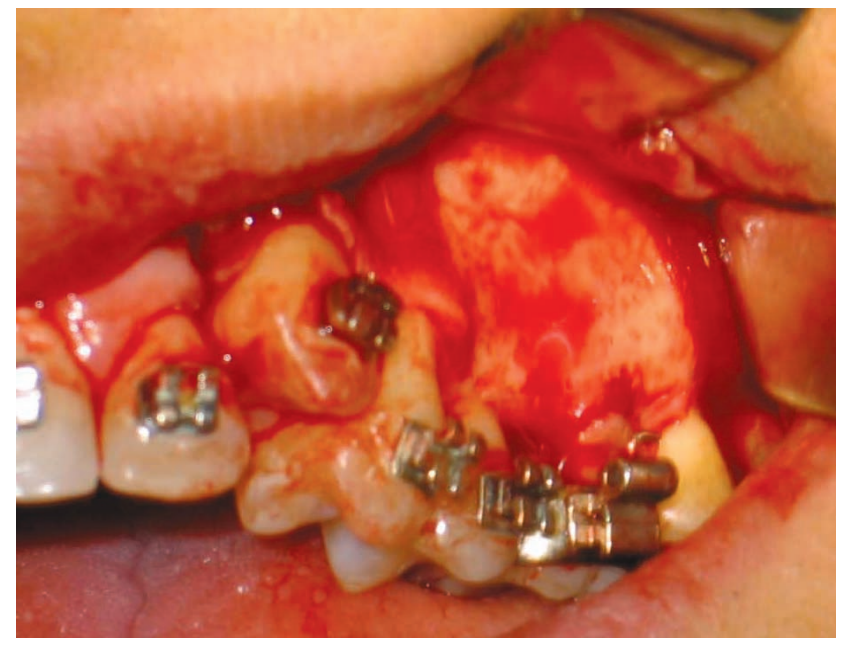

Fig. 24 


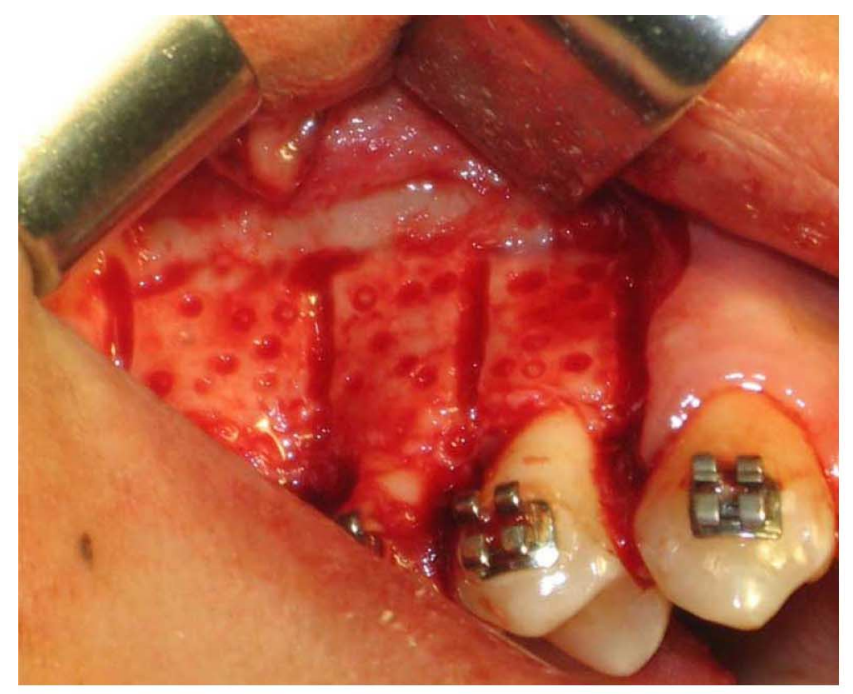

Fig. 25

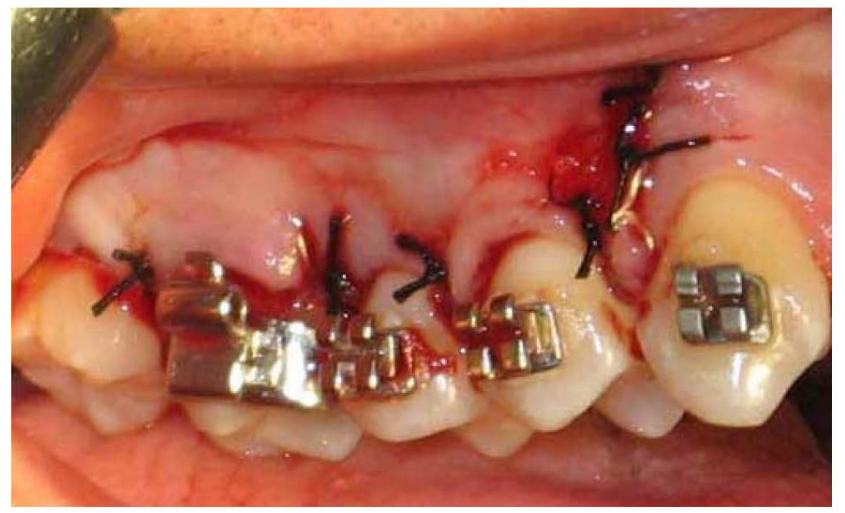

Fig. 27

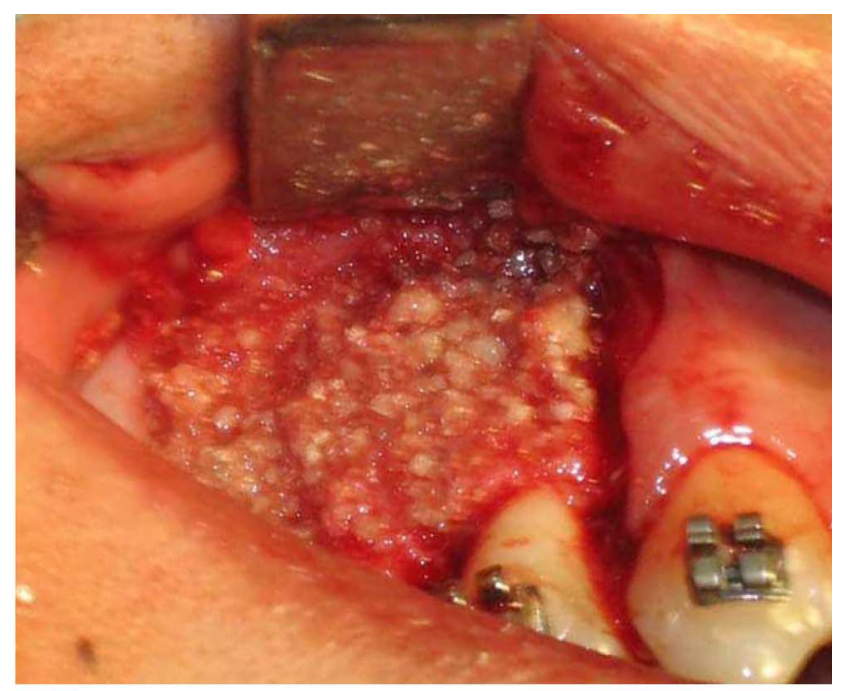

Fig. 26



Fig. 28

\section{CASO CLINICO 4}

Paciente de sexo femenino, 16 años, en tratamiento de ortodoncia (Fig. 29 A, B y C). Se indica exodoncia de terceros molares inferiores y verticalización quirúrgica de segundos molares mandibulares impactados (Fig. 30).
Se realiza exodoncia de terceros molares mandibulares (Fig. 31 A y B). Posterior verticalización quirúrgica de segundos molares impactados (Fig. 32A y B). Se estabiliza el molar y sutura el colgajo (Fig. 33 $A$ y $B$ )
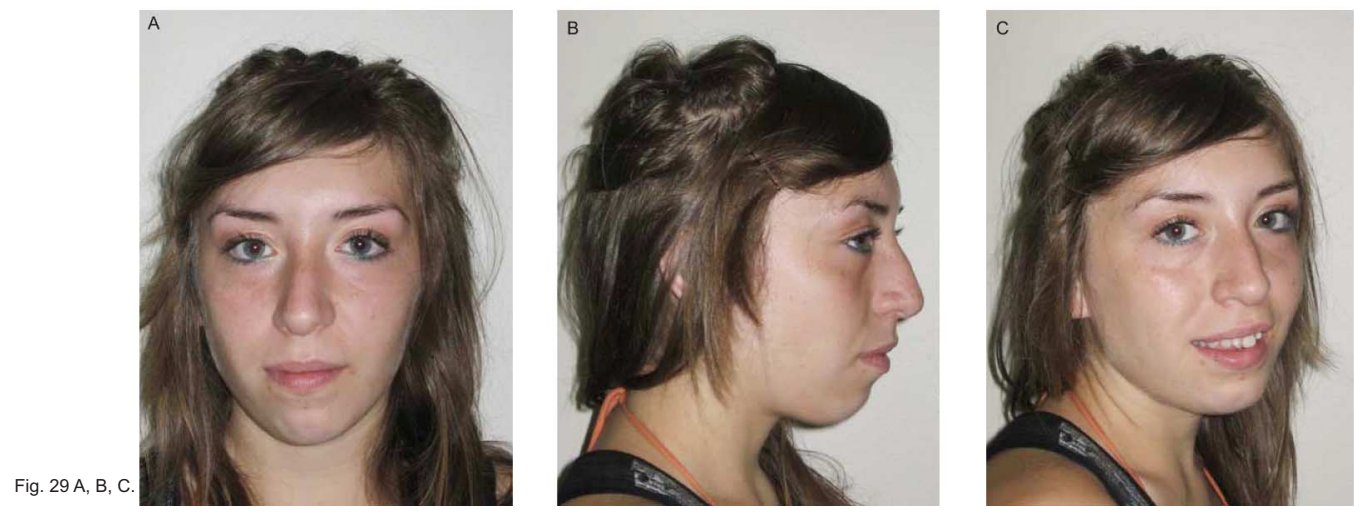

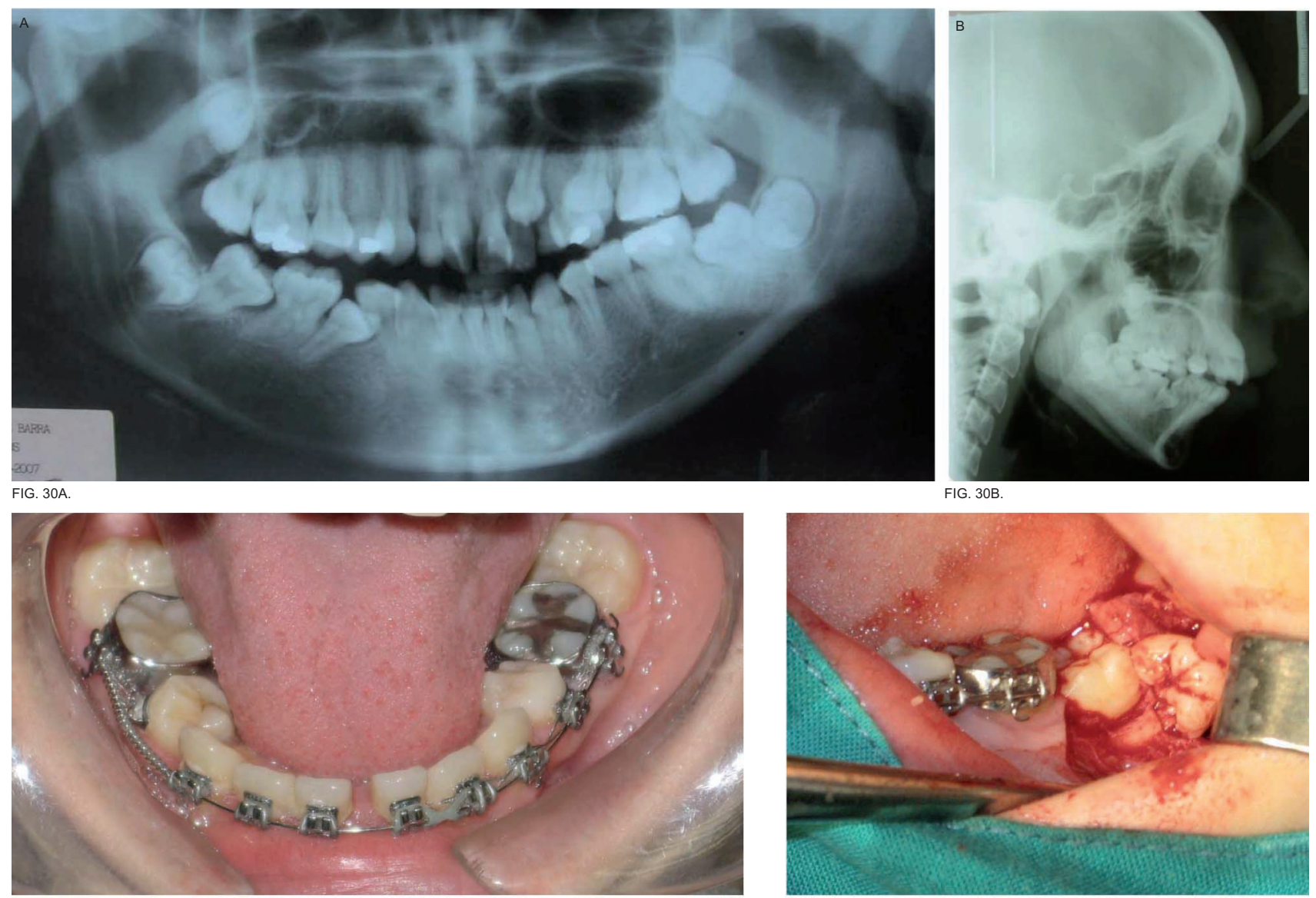

FIG. 30B.
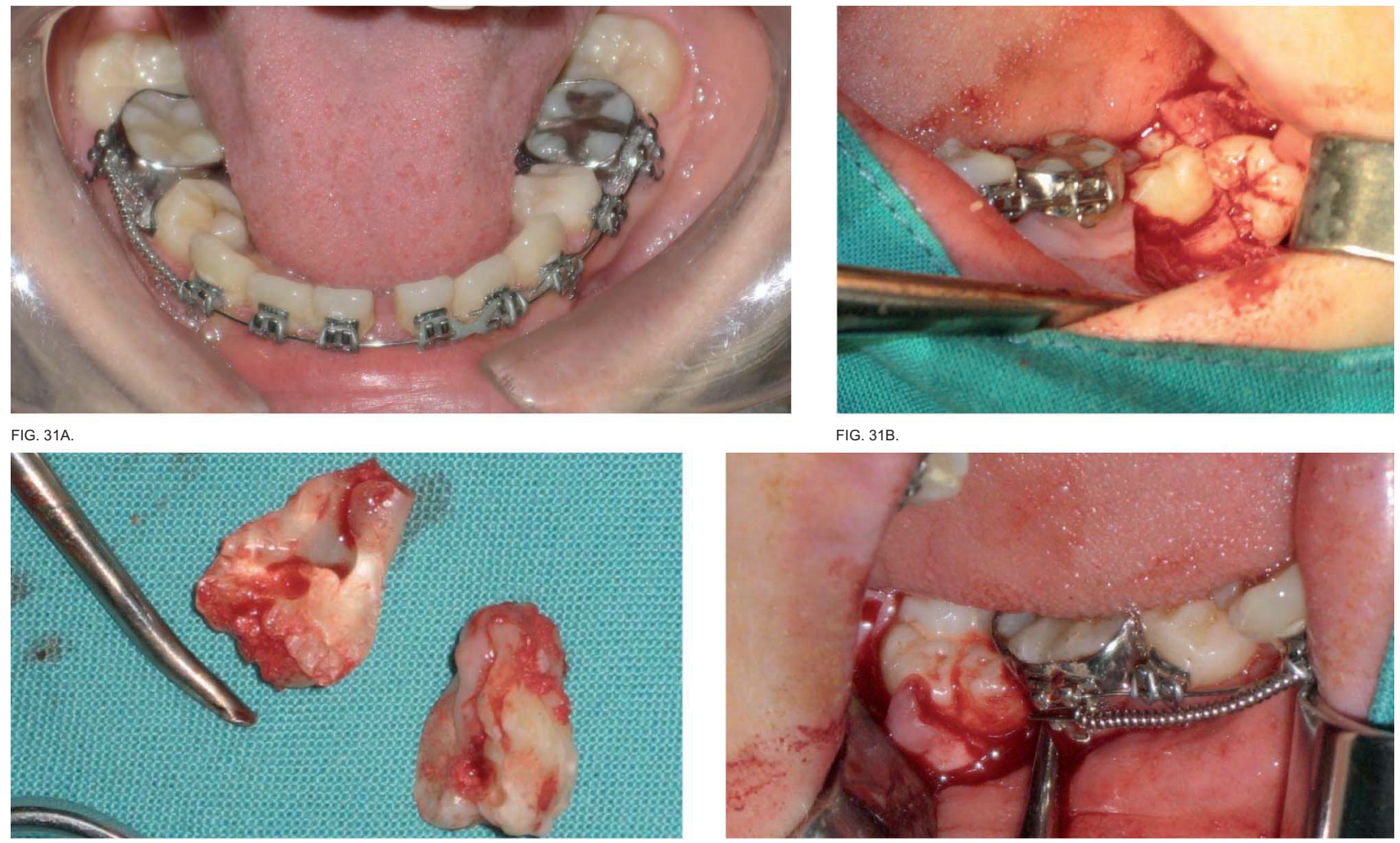

FIG. 31B.
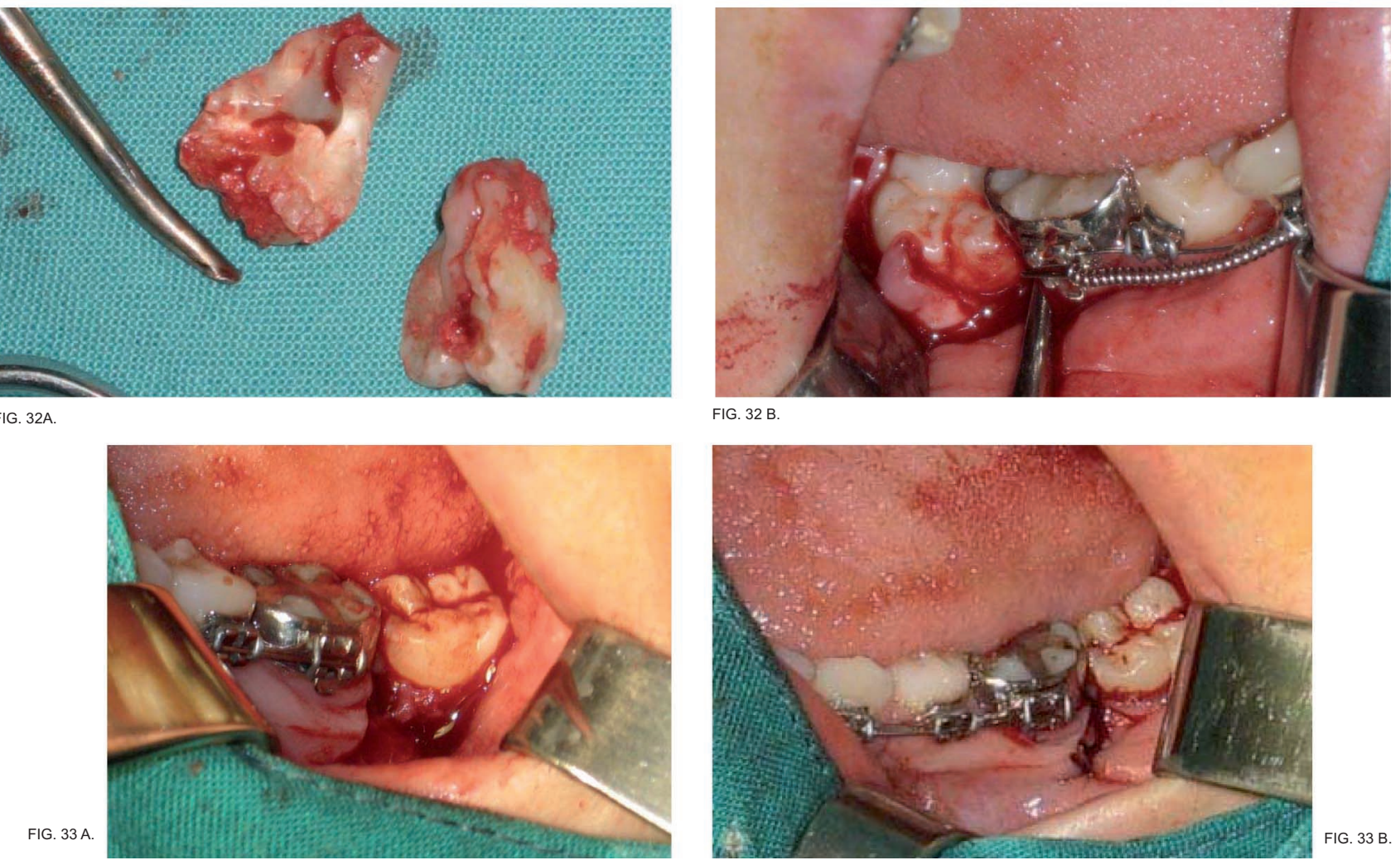
Como conclusión, se presentan 4 procedimientos periodontales de utilidad para la ortodoncia, sin embargo existe un sin numero de acciones que unen a ambas especialidades. El mejorar el trabajo en equipo y la comunicación entre el periodoncista y ortodoncista se reflejara en el éxito del procedimiento.

HOLMBERG, P. F.; HOLMBERG P. F.; HOLMBERG P. H. \& SANDOVAL, P. Periodontal applications to orthodontic.. Int. J. Odontostomat., 4(1):71-80, 2010.

ABSTRACT: El presente artículo tiene por objetivo dar a conocer cuatro procedimientos peridodontales de tipo quirúrgico que pueden The aim of this paper is to show four types of periodontal surgical procedures that may be useful for the orthodontist.

KEY WORDS: guided tissue regeneration (GTR), osseous graft, corticotomy.

\section{REFERENCIAS BIBLIOGRÁFICAS}

Akay, M. C.; Aras, A.; Günbay, T.; Akyalçin, S. \& Koyuncue, B. O. Enhanced effect of combined treatment with corticotomy and skeletal anchorage in open bite correction. J. Oral Maxillofac. Surg., 67(3):563-9, 2009.

Brown, I. S. The effect of orthodontic therapy on certain types of periodontal defects. I. Clinical findings. J. Periodontol., 44:742-56, 1973.

Campos, M.; Calvo, J. \& Santos, A. Regeneración tisular guiada con injerto óseo para el tratamiento de defectos periodontales infraóseos. A propósito de un caso. Rev. Oper. Dent. Endod., 5:63, 2007.

Diedrich, P. R. Orthodontic procedures improving periodontal prognosis. Dent. Clin. North Am., 40(4):875-87, 1996.

Ericsson, I.; Thailander, B.; Lindhe, J. \& Okamoto, H. The effect of orthodontics tilting movements in the periodontal tissue of infected and non infected dentition in dogs. J. Clin. Periodontol., 4:278-93, 1977.

Fischer, T. J. Orthodontic treatment acceleration with corticotomy-assisted exposure of palatally impacted canines. Angle Orthod., 77(3):417-20, 2007.

lino, S.; Sakoda, S.; Ito, G.; Nishimori, T.; Ikeda, T. \& Miyawaki, S. Acceleration of orthodontic tooth movement by alveolar corticotomy in the dog. Am. J. Orthod. Dentofacial Orthop., 131(4):448.e1-8, 2007.

Johnson, D. C. Prevalence of delayed emergence of permanent teeth as a result of local factors. J. Am. Dent. Assoc., 94:100-6, 1977.

Nowzari, H.; Yorita, F. K. \& Chang, H. C. Periodontally accelerated osteogenic orthodontics combined with autogenous bone grafting. Compend. Contin. Educ. Dent., 29(4):200-6; quiz 207, 218, 2008.

Oliveira, D. D.; de Oliveira, B. F.; de Araújo Brito, H. H.; de Souza, M. M. \& Medeiros, P. J. Selective alveolar corticotomy to intrude overerupted molars. Am. J. Orthod. Dentofacial Orthop., 133(6):902-8, 2008.

Pogrel, M. A. The surgical uprighting of mandibular second molars. Am. J. Orthod. Dentofacial Orthop., 108:180-3, 1995.

Stelzel, M. J. \& Flores-de-Jacoby, L. Guided tissue regeneration in a combined periodontal and orthodontic treatment: a case report. Int. J. Periodontics Restorative Dent., 18(2):189-95, 1998

Stelzel, M. \& Flores-de-Jacoby, L. The GTR technic within the framework of combined periodontalorthodontic treatments. A case report. Fortschr. Kieferorthop., 56(6):347-52, 1995.

Thailander, B. Infrabony pockets and reduced alveolar bone height in relation to orthodontic therapy. Semin. Orthod., 2:55-61, 1996.

Vanarsdall, R. L. Orthodontics and periodontal therapy. Periodontol., 9:132-49, 1995.

Varpio, M. \& Wellfelt, B. Disturbed eruption of the lower 
HOLMBERG, P. F.; HOLMBERG P. F.; HOLMBERG P. H. \& SANDOVAL, P. Aplicaciones periodontales a ortodoncia. Int. J. Odontostomat., 4(1):71-80, 2010.

second molar: clinical appearance, prevalence, and etiology. ASDC J. Dent. Child., 55:114-8, 1988.

Wilcko, W. M.; Wilcko, T.; Bouquot, J. E. \& Ferguson, D. J. Rapid orthodontics with alveolar reshaping: two case reports of decrowding. Int. J. Periodontics Restorative Dent., 21:9-19, 2001.
Dirección para correspondencia:

Fernando Holmberg Peters

Departamento Odontología integral

Facultad de Medicina

Universidad de la Frontera, Temuco

CHILE

Email: fernandoholmberg@yahoo.com

Recibido : 30-09-2009

Aceptado: 15-12-2009 